$10(1)(2021) 18-23$
Unnes Science Education Journal
Accredited Sinta 3

\title{
Physics Laboratory Management: A Novel Use of QR Code Tag on Physics Equipment Storage Cabinet
}

\author{
Ifa Rifatul Mahmudah ${ }^{\bowtie}$, Rifa'atul Maulidah
}

DOI: http://dx.doi.org/10.15294/usej.v10i1.40982

Physics Education, Teacher Training and Education Faculty, Universitas Siliwangi, Indonesia

\section{Article Info}

Submitted 21 September 2020 Revised 28 December 2020 Accepted 17 February 2021

\section{Keywords}

QR code, storage layout, physics laboratory

\begin{abstract}
The application of QR codes in laboratory management is an increase, but the study of its use in the physics laboratory equipment storage is rarely done. There are numerous in various laboratory equipment stored in the physics laboratory. Well-organized storage with QR-code installment in the cabinet should be a big consideration to assist laboratory users at trace and emplace the equipment in an appropriate. This study aims to develop the application of QR codes in designing the layout of laboratory equipment at the cabinet. The development of the storage layout of laboratory equipment refers to the research and development methods. There are two main focuses in this study, specifically are how to design the layout storage of laboratory equipment and how to develop the QR code scanning system in a physics laboratory. The questionnaire was distributed to 23 respondents, the highest result with $100 \%$ agreement shown when they assessed the utility of a QR code-based laboratory storage system and the design of a laboratory equipment layout. Speaking of the program performance of the QR code-based laboratory-item storage system, about $98 \%$ of respondents were satisfied. The laboratory users give a positive response to the laboratory management system that developed based on $\mathrm{QR}$ code. They consider the QR code system is an effective way of trace and emplace the laboratory equipment.
\end{abstract}

\section{How to Cite}

Mahmudah, I. R., \& Maulidah, R. (2021). Physics Laboratory Management: A Novel Use of QR Code Tag on Physics Equipment Storage Cabinet. Unnes Science Education Journal, 10(1), 18-23. 


\section{INTRODUCTION}

A real understanding of Physics is often accomplished by conducting laboratory activities. The nature of physics science itself as a process, attitude, and product requires a laboratory-based learning experience. As noted, the laboratory plays a role in physics learning. Anggereni \& Ikbal (2018) stated that a good laboratory certainly has a good impact on the achievement of the goals required by the curriculum. They further said that attention to the management of the laboratory is a must since it affects physics learning. The typical teaching structure for physics education majors at Universitas Siliwangi consists of at least three laboratory-based subjects each semester. According to the curriculum, almost all physics learning took place in the laboratory. A laboratory is no longer a place where physics equipment is stored. The deep meaning of the laboratory emphasized as a place where students carry out scientific activities on their own. These laboratory activities help students learn science and connect concepts to real-world situations in relevant ways (Wong et al., 2013). Trumper (2003) further said that scientific activities in the laboratory aim to achieved four categories, involves skills, concepts, the nature of science, and attitude.

Poor laboratory management most often being a barrier to the effectiveness of laboratorybased physics learning. That is the reason why Mohamad et al. (2012) stated that management and administration of laboratories are to determine that the process of testing in labs or workshops can be implemented effectively. Management of a science laboratory means the running and controlling of materials and human resources (Ezeano \& Ezeudu, 2013). Material resources management involves the arrangement and maintenance of the laboratory equipment, while human resources include teachers, laboratory technicians, and laboratory assistants. The problem arose when human resources are not doing their job in managing material resources properly, especially the management of laboratory equipment. According to (Priyambodo et al., 2017), proper management of the equipment in the laboratory is necessary to ensure accurate, reliable, and timely testing. Management of equipment emphasized how human resource recording laboratory equipment and organizing storage layout according to its characteristics and scope.

Over the past few decades, people found that a paper-based inventory system has a limitation. Considering the high risk of misplaced or losing equipment, there is a need for a more sys- tematic and user-friendly laboratory equipment management system. In this case, the QR code has high contributed to solving the problem. QR code is a machine-scannable image that was discovered by the Denso Wave Company in 1994. The user needs to download the QR code reader application into a mobile phone. Then the user points the camera of the mobile phone and scans the QR code for getting some product information.

These days, so much attention has been paid to the implementation of $\mathrm{QR}$ codes on laboratory inventory. Shukran et al. (2017) developed chemical inventory management using a mobilebased QR in the National Defence University of Malaysia's (NDUM) chemical laboratory. Due to chemical reactivity danger, they labeled each chemical container with a color-coded QR tag sticker. Users had to point the QR code reader on the sticker. Then the information can be retrieved, including quantity, date purchased, disposal scheduled. The implementation of the QR code was successful based on surveys of the users. Another year later, Wangsa; Prastyo (2019) implemented a work instruction document in the chemistry laboratory, Universitas Gajah Mada. Document instruction consists of a laboratory equipment list and pieces of the equipment labeled by $\mathrm{QR}$ code. Whenever a user scans the QR code label, information about the operation step of the equipment will pop up. The implementation of a QR code based-inventory has found proven effectively used than a manual inventory system. Mamin et al. (2017) also designed QR codes in Science Laboratory, Universitas Negeri Makasar. There was no enough information about the effectiveness of the implementation. Another research conducted by Rochmawati et al. (2018) also shown that a responsive web-based QR code inventory was proven effective in the laboratory of informatics, Universitas Negeri Surabaya.

As noted, several studies about QR codebased inventory system has carried out, but most of them were emphasize only equipment name, quantity, specification, and work instruction. Another part of the inventory system that needs to be addressed, including the storage location of the laboratory equipment. As known, a lot of equipment stored in the physics laboratory and study concerning the QR code use in physics laboratory equipment storage is rare. Sutrisno (2010) classified this physics equipment into mechanics, heat, waves, optics, magnetism and electromagnetism, modern physics, earth and space sciences, measurement tools, supply tools, containers, repair tools, consumable material and 
equipment, and fixed equipment. Therefore, an inventory system equipped with storage location information and well-organized storage comes with labeled shelves that must be a huge consideration to help human resources in tracking and returning the equipment from and to the appropriate labeled-cabinet. At Basic Physics Laboratory Siliwangi University, there is no laboratory technician and laboratory assistant. As a result, lecturers have an overwhelming workload. They have to prepare and handle all the necessary laboratory activities as well as teach and guide the course. That is why a well-organized and easily accessible equipment storage will help to avoid more time-consuming to accomplish this job desk. Moreover, the available cabinet in the Basic Physics Laboratory is not a glass-front cabinet storage type but a wooden cabinet. This type of cabinet makes the user take a long time to track laboratory equipment inside the cabinet.

Based on these needs, this study intended to develop a QR code-based laboratory item-storage layout for Physics Laboratory at Universitas Siliwangi as a part of the laboratory inventory system.

\section{METHOD}

The two main parts of this study were focusing on how to re-organize laboratory equipment storage and make the QR code scanning system. Laboratory item-storage layout development refers to research and development by (Borg $\&$ Gall, 1983). Here, the stages are limited to four. Complete research and development stages are presented in Figure 1.

This study was conducted at Basic Physics Laboratory Siliwangi University under the supervision of the Head of Laboratory. To make a better QR code-based laboratory-item storage layout, tight discussion with other fellow lecturers was carried out during the study.

At the end of the research, a 10-statement questionnaire was administered to 23 respondents. Of these, five were lecture while others were students. The fixed response (i.e. yes/no) questionnaire focused on respondents' perceptions towards the utility, design, and program performance of QR-code based storage layout. The questionnaire is also equipped with a textbox for comment at the end. The selected response was analyzed using quantitative descriptive and reported in percentage of each aspect.

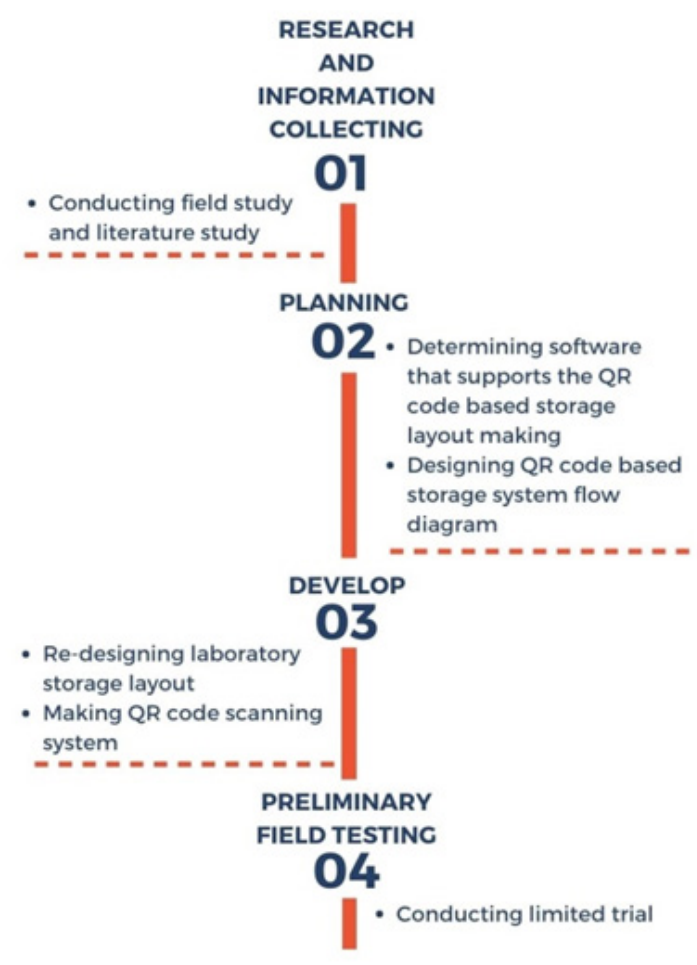

Figure 1. Research and development stages took in this study

\section{RESULT AND DISCUSSION}

Based on the need analysis at the beginning of the first stage, there was an accessible QRcode based storage layout development needed. This stage continued with determining supporting software for re-organizing equipment storage and making the QR code scanning system. Some software selected for re-organizing equipment storage, there were sketch up for designing storage layout, and byte scout barcode generator for generating links into QR code.

Turning the listed ideas into a product was began at the development stage. At this stage, the activities divided into two parts; there were re-organizing the storage layout and making a QR code scanning system. Since there was no complete inventory at Basic Physics Laboratory Siliwangi University, hence the first task would be recording laboratory equipment in a Microsoft Excel document. The information recorded contains the code, name, quantity, specification, and storage location of each laboratory equipment. Once we have completed the list, the stage continued by taking a picture of the equipment. The image was needed as output information retrie- 
ved from the database. To make well-organized storage, designing a storage layout shown in $\mathrm{Fi}$ gure 2 was a must.

The storage layout picture was printed and placed in the laboratory. This storage layout picture guided lecturers in storing the equipment into the cabinet. The available cabinet in the Basic Physics Laboratory is a wooden cabinet-type that consisted of shelves. Later, at the next step, each shelf door was labeled with a different QR code tag according to the layout design in Figure 2.

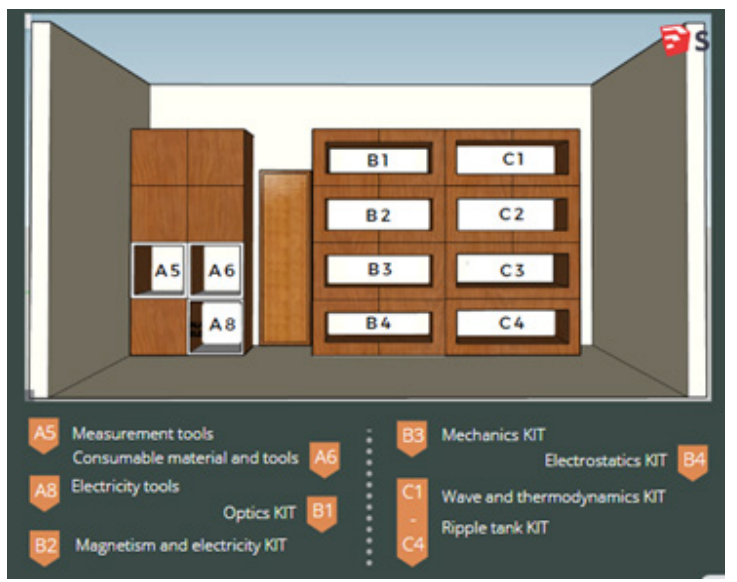

Figure 2. Storage Layout

Before the process of making a QR code scanning system begins, preparing data that would be stored in the database was needed. The data is a JPEG file of each laboratory equipment contains a picture, code, name, storage location, and specification. The process of making the QR code scanning system is quite simple. Hence, advanced computer skills were not required. The step refers to Green et al., (2017) with slight modification. The process is presented graphically in Figure 3.

The setup of the scanning system consisted of five steps. The steps took less time as long as the internet connection was good. There was no cost associated with the scanning system making. All of the laboratory equipment data images were uploaded into google drive over an available Wi-Fi connection. Then the QR codes of this equipment were constructed on free portable software (byte scout generator) downloaded before. The only additional cost was to purchase a paper sticker. In the third step, QR code tags were printed on this sticker paper. QR code tag was a $90 \mathrm{~mm} \times 80 \mathrm{~mm}$ sticker-card attached

to each door of the laboratory cabinet. Each QR code tag has a different color according to the equipment group, such as a brown $\mathrm{QR}$ code tag sticker is for measurement tools. The brown QR code tag was placed on the cabinet door, shelf A5.

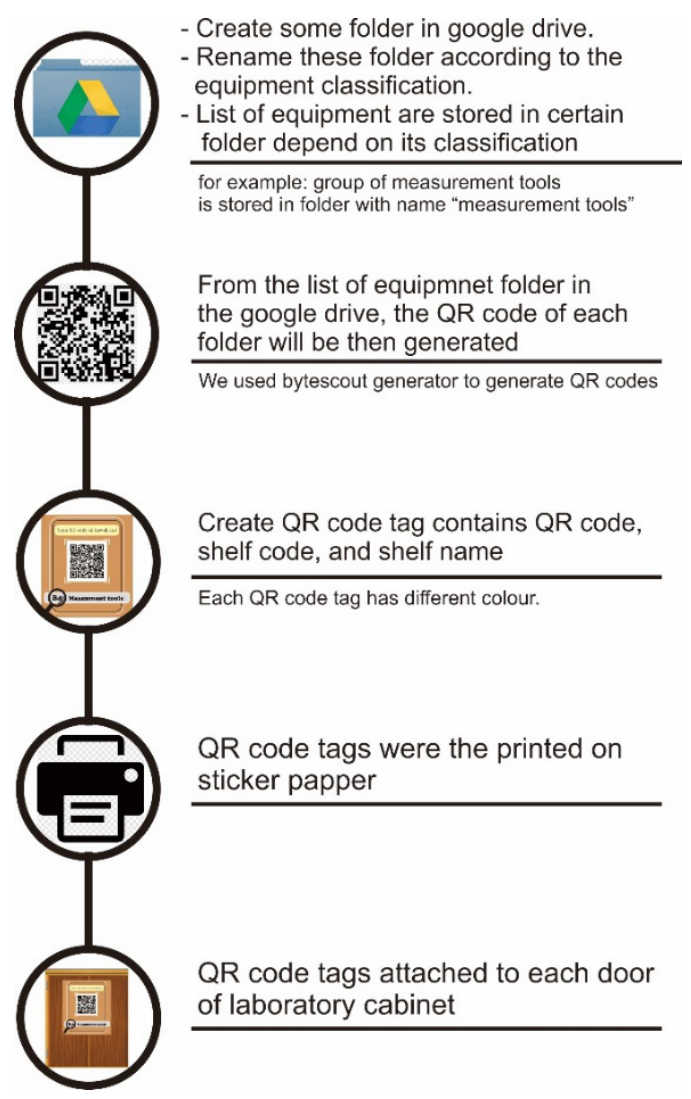

Figure 3. Flow chart indicating steps taken for making a QR code scanning system.

At the end of the R\&D stages, a limited trial was conducted. Five lecturers and eighteen students tried to operate QR code-based laboratory-item storage following the flow diagram shown in Figure 4.

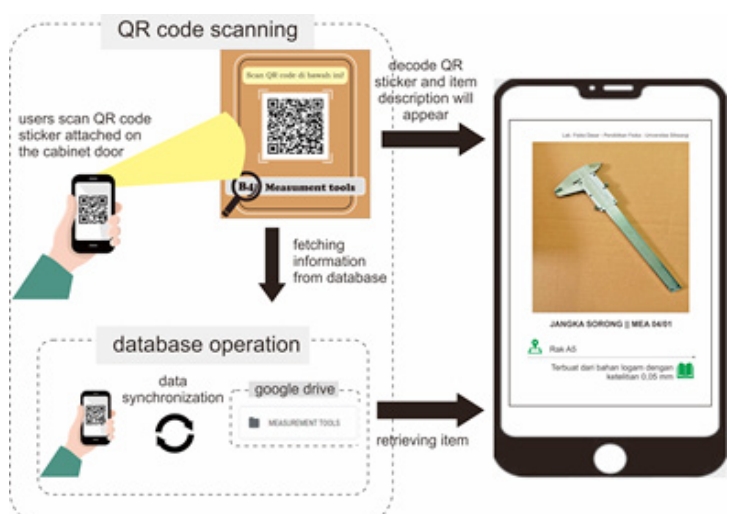

Figure 4. QR code flow diagram

All users were enthusiastic about trying the QR code-based laboratory-item storage despite some are still confused because the QR code 
reader on their smartphone was slightly different from the one exemplified by the researcher. Users scanned the QR code tag on a cabinet door with a Wi-Fi/ cellular using the free application (fastest barcode scanner) that downloaded on users' smartphones. Then users receive information about what equipment was placed inside the cabinet. Overall, they showed a positive response to the new storage layout system that will take over the previous old storage layout. Through a questionnaire, each aspect of QR code-based laboratory-item storage was rated. The result is presented in Figure 5.

Based on the result of the questionnaire administered to the 24 respondents in Figure 1, 100\% of respondents gave a positive-view to the utility aspect of the QR code-based laboratory-item storage system. They agreed that this new system makes users easier to track laboratory equipment as part of the effort to increase the laboratory management system. Easily accessible equipment storage will help to avoid more time-consuming for users. It can be said that the implementation of QR code based-inventory found proven effectively used than a manual inventory system.

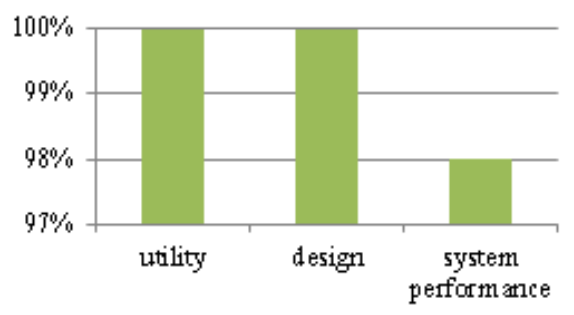

Figure 5. Result of Respondents perception toward QR code-based laboratory storage layout

This result is in line with the research conducted by Riswanto et al. (2019)until now many school laboratories have not functioned well in supporting the learning process. One of the causes that there is no practical and efficient laboratory management system. Laboratory work now feels very complex which requires persistent. On the other, technology is developing very rapidly in the current era of the 4.0 industrial revolution, which is demonstrated by cyber technology. This cyber system provides an opportunity to develop a laboratory management system that is easier both in administration and management. Therefore the purpose of this study is the development of management systems for industrial revolutionary school laboratories 4.0. This development research method includes needs analysis (implemented. The study shows that the efficiency of time in the use of school laboratories with an online system was proven. Accessible equipment storage will help to avoid more time-consuming to prepare the experiment apparatus needed. Further, users not only enable to retrieve information about equipment located inside the cabinet, but also can get the real picture, name, code, and specification of each laboratory equipment. Well-organized storage with QR code-based labeled-cabinet layout also kept equipment continue to sit on the cabinet.

The high-frequency agreement also showed when the respondents asked to assess the design of the QR code-based laboratory-item storage system. All respondents agreed that the image of equipment is clear, the font selection and font size is correct, and proportions of the image and writing are quite fit.

Speaking of the program performance of the QR code-based laboratory-item storage system, about $2 \%$ of respondents were not satisfied with the program performance. The QR codebased laboratory-item storage system was not friendly to use for them. This system was still new to some respondents. This dissatisfaction may be influenced by the lack of skills to operate the QR code reader. Indeed, the ease of access and use of systems depends on how often users try to use it. The unstable internet connection also was being a barrier to better system performance.

The QR code-based system is not without limitations. Some flaws need to be taken into consideration regarding the type of database selection. An unstable internet connection makes the process of retrieving laboratory equipment did not run smoothly. Using the type of database system without an internet connection requirement could be a further study that needs to develop.

\section{CONCLUSION}

The study highlighted the need for better laboratory-item management. In summary, a QR code-based laboratory item-storage layout developed as planned. The QR code-based system managed to run as it is despite there was some limitation need to be addressed to fit the requirements. Based on the limited trial was carried out at the end of this study, overall, the respondents gave positive responses. They viewed the QR code-based system as an effective way of storing and tracking laboratory equipment as well as retrieving complete information about laboratory equipment. 
Ifa Rifatul Mahmudah, Rifa'atul Maulidah / Unnes Science Education Journal 10 (1) (2021) 18-23

\section{REFERENCES}

Anggereni, S., \& Ikbal, M. S. (2018). Analysis of Physics Laboratory Management at The Northern Region of Makassar's State Senior High Schools By Standard of Facilities and Infrastructure. Jurnal Ilmiah Pendidikan Fisika AlBiruni, 7(1), 41.

Borg, W., \& Gall, M. (1983). Educational Research: An Introduction 4th edition Longman Inc. New York.

Ezeano, A., \& Ezeudu, F. (2013). Application of laboratory management skills by chemistry teachers in Enugu state. Journal of Education and Practice, 4(18), 159-165.

Green, T., Smith, T., Hodges, R., \& Fry, W. M. (2017). A simple and inexpensive way to document simple husbandry in animal care facilities using QR code scanning. Laboratory Animals, 51(6), 656-659.

Mamin, R., Saenab, S., \& Muhiddin, N. H. (2017). Inventarisasi Alat dan Bahan Laboratorium IPA dengan Fitur Quick Response Code (QC Code). 1(1), 94-105.

Mohamad, Z., Mohammad Yasin, R., \& Ab Rahman, M. N. (2012). Laboratory Quality Management Requirements of Engineering at the Polytechnics Ministry of Higher Education Malaysia. Journal of Education and Learning (EduLearn), 6(1), 59.

Priyambodo, E., Wiyarsi, A., \& Nugraheni, A. (2017). Chemistry Laboratory Equipment Inventory Media: An Alternative Media for Students' in Learning of
Laboratory Management. 3(October), 2476-9533. Riswanto, Suseno, N., Partono, Harjati, P., \& Dedy, H. A. (2019). School Laboratory Management Information System. Journal of Physics: Conference Series, 1361(1).

Rochmawati, N., Anistyasari, Y., Suyatno, D. F., \& Kurniawan, I. F. (2018). A Responsive WebBased QR Code for Laboratory Clearance Form. Journal of Physics: Conference Series.

Shukran, M. A. M., Ishak, M. S., \& Abdullah, M. N. (2017). Enhancing Chemical Inventory Management in Laboratory through a MobileBased QR Code Tag. IOP Conference Series: Materials Science and Engineering, 226(1).

Sutrisno. (2010). Laboratorium Fisika Sekolah I. Universitas Pendidikan Indonesia.

Trumper, R. (2003). The Physics Laboratory - A Historical Overview and Future Perspectives. Science and Education, 12(7), 645-670.

Wangsa; Prastyo. (2019). Implementasi Quick Response ( QR ) Code Pada Dokumen Instruksi Kerja Alat Laboratorium Kimia. Jurnal Pengelolaan Laboratorium Pendidikan, 1(2), 48-53.

Wong, S. S., Firestone, J. B., Luft, J. A., \& Weeks, C. B. (2013). Laboratory Practices of Beginning Secondary Science Teachers: A Five-Year Study. Science Educator, 22(1), 1-9. https://library.iau. edu.sa/docview/1438027978?accountid=136 546\%0Ahttp://by7nn3rg6h.search.serialssolutions.com/?genre $=$ article $\&$ sid $=$ ProQ: $\&$ atitle $=$ Laboratory+Practices+of+Beginning + Second ary + Science + Teachers $\% 3 \mathrm{~A}+\mathrm{A}+$ Five-Year + St udy \& title $=$ Science + Educator $\&$ issn $=10$ 